\title{
Design analysis of Hub, Rim and Drum in Brake Assembly
}

\author{
Ramamurti V. ${ }^{1}$, Sukumar T. ${ }^{2}$, Mithun S. ${ }^{2}$, Prabhakar N. ${ }^{2}$ \& Hudson P. V. ${ }^{2}$ \\ ${ }^{1}$ Retired Professor-Indian Institute of Technology Madras, India \\ ${ }^{2}$ WABCO India Ltd, Chennai, India \\ Correspondence: Ramamurti V., Retired Professor-Indian Institute of Technology Madras, India. E-mail: \\ ramamurti@hotmail.com
}

Received: February 27, 2013

Accepted: March 27, 2013 Online Published: May 2, 2013

doi:10.5539/mer.v3n1p170

URL: http://dx.doi.org/10.5539/mer.v3n1p170

\begin{abstract}
Stress analysis connected with the brake assembly of heavy vehicles is a complicated problem in view of the machine elements involved. The hub (on the rear axle), the rim (holding the wheel) and the drum (holding the brake shoe) experience severity of loads. While the vehicle is being driven the power is transmitted from the hub to the rim. When the brake is applied, the brake drum receives the braking torque and communicates it to the rim. Analysis associated with braking is actually transient since the braking torque varies with time in a short period of time whereas the one associated with driving is predominantly steady while the vehicle moves with uniform speed. None of them can be considered rotationally symmetric. Even though 3D brick element can be used for modelling all the three members, the computational effort needed to handle the problem of braking becomes extremely cumbersome. Hence a compromise solution is presented in this paper.
\end{abstract}

Keywords: drum brake, design analysis, input forces, finite element application, 3D brick, axisymmetric concept

\section{Nomenclature}

a-Acceleration, $\mathrm{m} / \mathrm{s}^{2}$

$\mathrm{p}_{\mathrm{r}}-$ Radial Pressure,bar

$\mathrm{p}_{\theta}$-Tangential Pressure, bar

r-Effective radius of the wheel, $\mathrm{m}$

t-Time, $s$

A-Front area, $\mathrm{m}^{2}$

J-Polar moment of inertia Nmms ${ }^{2}$

\author{
$\mathrm{R}_{\mathrm{r}}-$ Rolling resistance, $\mathrm{N}$ \\ $\mathrm{R}_{\mathrm{a}}-$ Air resistance $\mathrm{N}$ \\ $\mathrm{W}$-Weight of the vehicle $\mathrm{N}$ \\ $\mathrm{K}-$ Coefficient of rolling resistance \\ $\mathrm{K}_{\mathrm{a}}$-Coefficient of air resistance \\ $\alpha$-Angular acceleration $\mathrm{rad} / \mathrm{s}^{2}$ \\ $\theta-$ Circumferential location
}

\section{Introduction}

Design of automobile systems covering brake dynamics, design of wheel brakes, analysis of brake components using finite element is reported by Bent and Bill (2008). There are works on drive systems as reported by Fenina et al. (2008), vehicle transmission by Popovic et al. (2012), Rose (2011), on shafts by Croccolol and Vincenzil (2009) and Paynter et al. (2009) and Cao et al. (2009) and Sun et al. (2009). However there are a few papers of direct relevance to hub, rim and drum. Drum brake and disk brake interface pressure are presented by Day (1991) and Tirovic and Day (1991). The present analysis addresses the complexities associated with these three transmission elements.

The hub assembly along with brake drum and rim as shown Figure 1 is subjected to driving torque and braking torque during driving and braking respectively. In order to check the design adequacy of the hub under extreme load conditions stress analysis needs to be carried out. The hub of the rear axle is connected to the drum by ten bolts and to the rim holding the tire by the same set of bolts. The hub and the rim take the load while driving, whereas while braking the drum and the rim. With the bolting arrangement between the removable parts, modelling all the three together as made up of $3 \mathrm{D}$ brick is ideal. But since the brakes act for a short period of 
time, transient analysis becomes extremely complicated. Two approaches are presented in this paper. The first to model using 3D brick, the second ignoring the influence of the ten bolts holding the detachable parts together, by using rotationally symmetric element subjected to asymmetric loading (expressed as Fourier series) are compared to make sure that the two approaches give the same order of stresses.
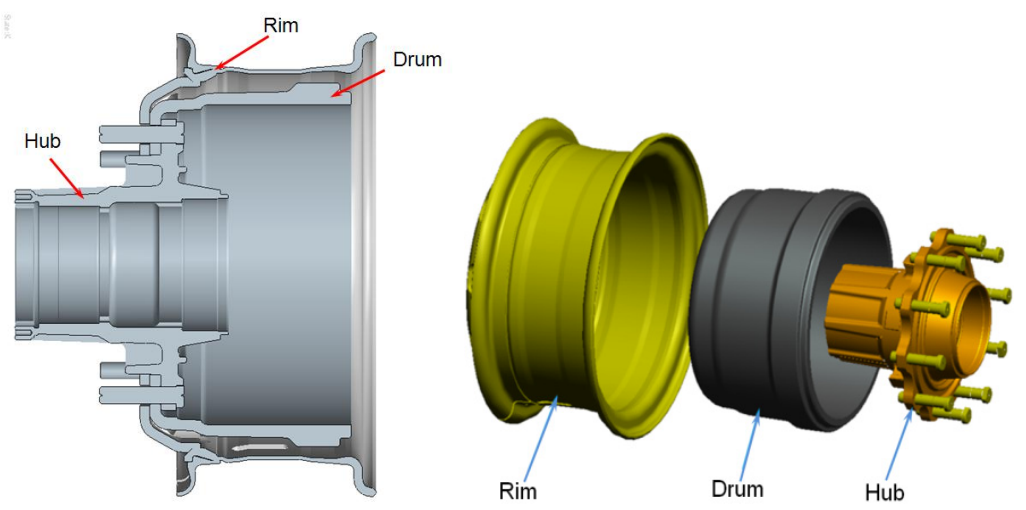

Figure 1. Drive unit Assembly

\section{Units Investigated}

\subsection{Details of Vehicle}

The specification of a typical vehicle designed is as shown in Table 1 and the material properties of the three parts in Table 2.

Table 1. Vehicle specification

\begin{tabular}{cc}
\hline Description & Value \\
\hline Max. Engine Output Torque & $93.5 \mathrm{~kW}(125.3 \mathrm{HP})$ at $2500 \mathrm{rpm}$ \\
Max. Torque & $410 \mathrm{Nm}$ at $1400-1700 \mathrm{rpm}$ \\
Gross Vehicle Weight & 16 tonne \\
Max geared speed in top gear & $81 \mathrm{kmph}$ \\
Gradability & $17 \%$ \\
Number of wheels & 6 \\
Overall gear reduction in top gear & 5.857 \\
\hline
\end{tabular}

Hub: The wheel hub is to withstand the vehicle load, cornering effect and impact load due to road undulation. In general, the material used for hub is of forged steel (C45).

Drum: The brake drum is generally made of a special type of cast iron which is heat-conductive and wear-resistant. It is positioned very close to the brake shoe without actually touching it, and rotates with the wheel and axle. As the lining is pushed against the inner surface of the drum, friction heat can reach as high as $600{ }^{\circ} \mathrm{C}$.

Rim: The rim is manufactured by cold rolling the "outer edge of wheel, holding the tire". It makes up the outer circular design of the wheel on which the inside edge of the tire is mounted on commercial vehicles. 
Table 2. Material property

\begin{tabular}{clccc}
\hline S. No & Property & Hub & Drum & Rim \\
\hline 1 & Material & $45 \mathrm{C} 8$ & FG 200 & St 370 \\
2 & Young's Modulus $\left(\mathrm{N} / \mathrm{mm}^{2}\right)$ & $2.1 \times 10^{5}$ & $1.1 \times 10^{5}$ & $2.1 \times 10^{5}$ \\
3 & Poison's ratio & 0.30 & 0.26 & 0.30 \\
4 & Ultimate tensile strength $\left(\mathrm{N} / \mathrm{mm}^{2}\right)$ & 640 & 200 & 370 \\
5 & Yield strength $\left(\mathrm{N} / \mathrm{mm}^{2}\right)$ & 520 & 100 & 240 \\
6 & Density $\left(\mathrm{N} \cdot \mathrm{sec}^{2} / \mathrm{mm}^{4}\right)$ & $7.85 \times 10^{-9}$ & $7.2 \times 10^{-9}$ & $7.85 \times 10^{-9}$ \\
7 & Endurance limit $\left(\mathrm{N} / \mathrm{mm}^{2}\right)$ & 320 & 80 & 120 \\
\hline
\end{tabular}

\subsection{Resistance to Motion}

Total resistance experienced by the vehicle can be expressed as

$$
\mathrm{R}=\mathrm{R}_{\mathrm{r}}+\mathrm{R}_{\mathrm{a}}
$$

where the rolling resistance $\mathrm{R}_{\mathrm{r}}$ is equal to $\mathrm{kW}$, normally coefficient of rolling resistance $\mathrm{k}$ is taken as 0.015 Wong (2001).

Air resistance $\mathrm{R}_{\mathrm{a}}$ is given by

$$
\mathrm{R}_{\mathrm{a}}=\mathrm{K}_{\mathrm{a}} \mathrm{AV}^{2}
$$

where the typical coefficient of air resistance $K_{a}$ is taken as 0.045 Wong (2001).

For a vehicle with maximum velocity of $81 \mathrm{kmph}$ and frontal area $4 \mathrm{~m}^{2}$, the overall resistance offered by the motion of vehicle works out to $3580 \mathrm{~N}$.

\subsection{Power and Tractive Effort}

Based on the vehicle specification(truck) driving and braking torque for the vehicle are arrived at from horse power and tractive effort of the vehicle which are shown in Figure 2, Wong (2001).

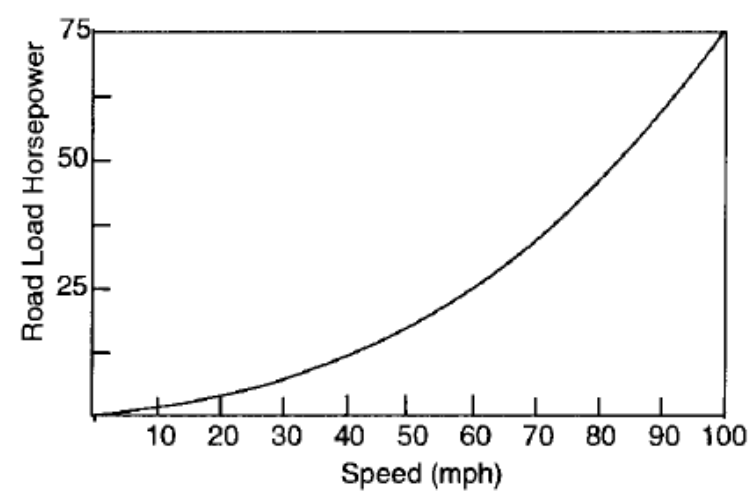

Road load Power Plot

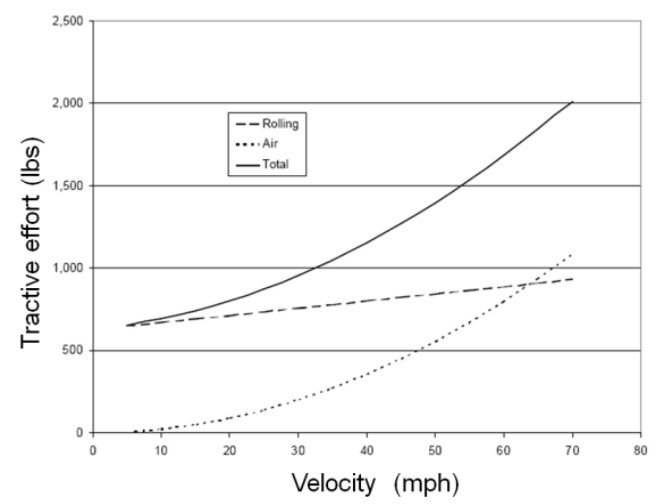

Tractive effort

Figure 2. Power and tractive effort 


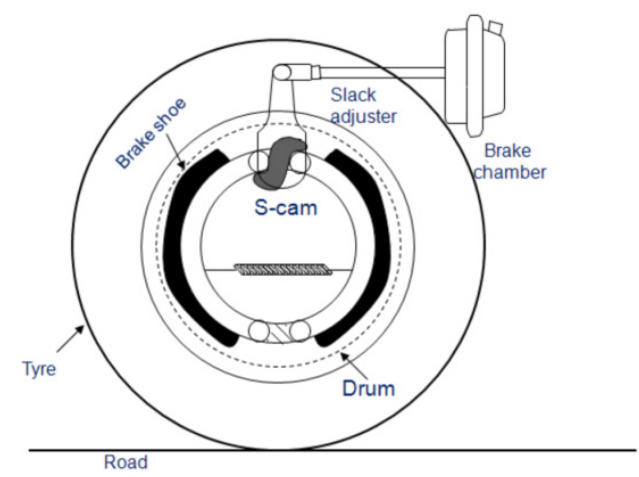

Figure 3. Schematic representation of drum brake assembly

Figure 3 shows the brake drum assembly. In this Figure the drum and the tyre are rotating members. The two parts of the brake shoe move towards the brake drum while the brake is applied with the help of S-cam.

\subsection{Vehicle Braking History}

The stopping time and braking force have been arrived at from actual vehicle field test data during the panic condition. The maximum braking force is achieved within 2 seconds reached zero in around 6 seconds. The detailed braking force and time history are shown in Figure 4 and the brake drum details in Table 3.

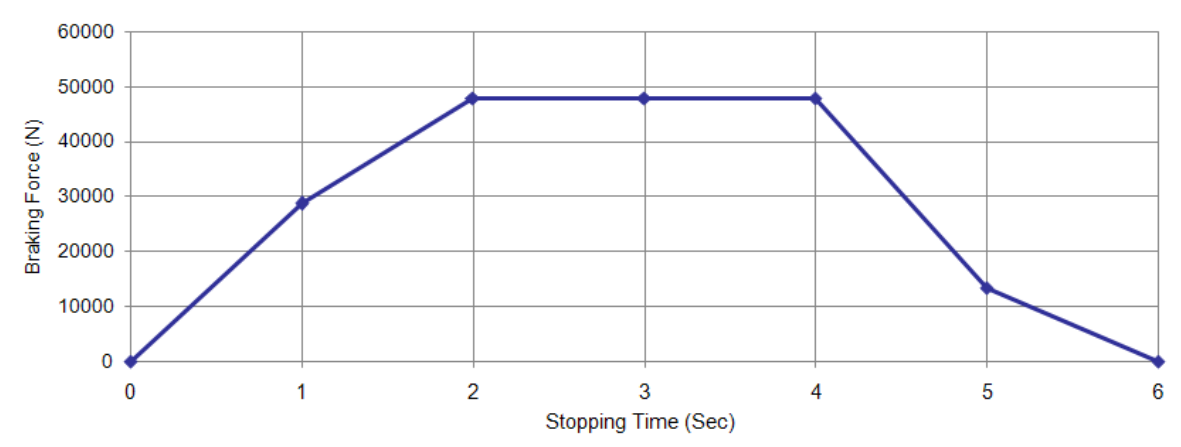

Figure 4. Vehicle braking history

Table 3. Drum brake details

\begin{tabular}{cll}
\hline S. No & Description & Specification \\
\hline 1 & Drum Diameter (D) & $410 \mathrm{~mm}$ \\
2 & Operating Pressure & $7.2 \mathrm{bar}$ \\
3 & Brake Chamber output force & $11150 \mathrm{~N}$ \\
4 & ASA Arm Length & $160 \mathrm{~mm}$ \\
5 & S-Cam Tip Radius & $13 \mathrm{~mm}$ \\
6 & Mechanical Efficiency & 0.96 \\
\hline
\end{tabular}

\subsection{Verification of Braking Torque}

$\mathrm{S}$ - Cam shaft torque $=$ Brake chamber output force $\mathrm{x}$ lever length

$\mathrm{S}$ - Cam shaft torque $=11150 \times 0.16=1784 \mathrm{Nm}$

Brake shoe tip effect $=\mathrm{S}-$ Cam shaft torque/Effective cam radius $=1784 / 0.013=137230 \mathrm{~N}$

Braking force acting on drum $=$ Brake shoe tip effect $\times$ Brake factor $\times$ Mechanical efficiency $=137230 \times 0.55 \times 0.95=$ $71703.076 \mathrm{~N}$;

Braking torque $=$ Braking force acting on drum $x$ Drum radius $=71703.076 \times 0.205=14700 \mathrm{Nm}$;

The information compiled in the section is being made use of subsequently at appropriate places. 


\section{Boundary Conditions and Loading}

Figures 5 to 10 show the rotating elements (the hub, the drum and the rim) of the drive system. The typical commercial hub assembly with overall dimensions is shown in Figure 5.

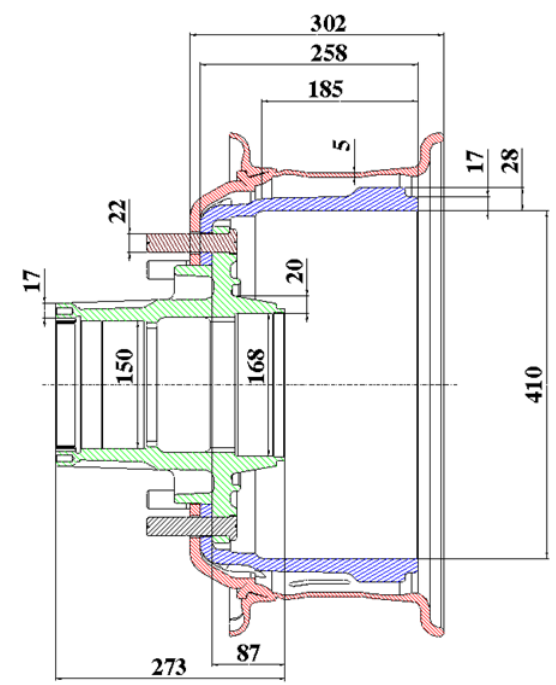

Figure 5. Typical dimension in $\mathrm{mm}$ of the drive unit assembly

The rim is assumed to have no circumferential displacement on the free face shown in Figure 6. The local influence of bolted joints is ignored. The bearing locations of the hub are assumed to have no displacement along the radial and axial directions.

The normal inflating pressure of a heavy vehicle is 5.58 bar ( $80 \mathrm{psi}$ ) acting radially inwards on the rim as shown in Figure 7. Since the hub is connected to the drive axle through spline, the driving torque is assumed to be transmitted to the hub through the splines with uniform intensity as shown in Figure 8. Besides while braking torque is assumed to act on the inner periphery of the drum for $220^{\circ}$ through the two brake shoes as shown in Figure 9. Besides the vehicle experiences inertia force, inertia torque and force required to overcome air resistance which when estimated are quiet small in comparison with other loads.

To check the accuracy of the results obtained by the 3D brick element when the vehicle is subjected to internal pressure, driving torque and braking torque (Section 4 and 5), use of axisymmetric element subjected to asymmetric loading is also employed (Section 6).

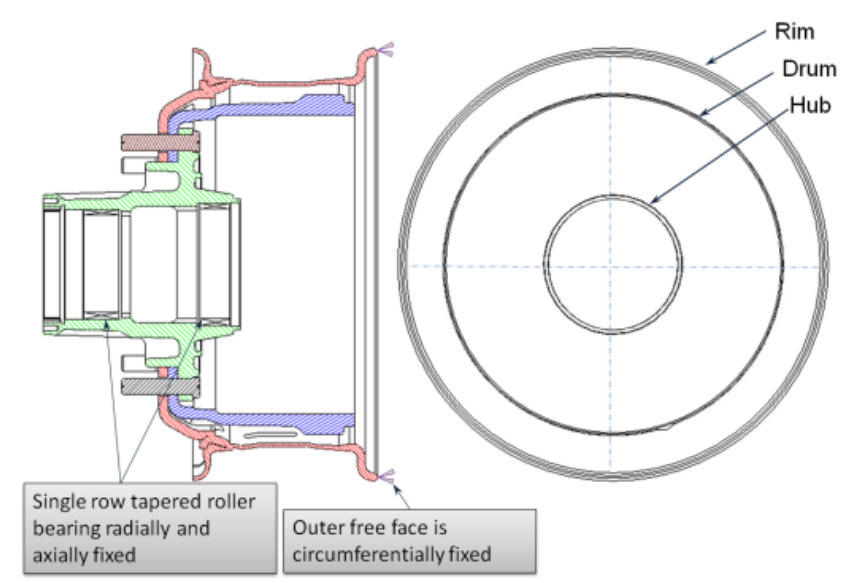

Figure 6. Boundary conditions 


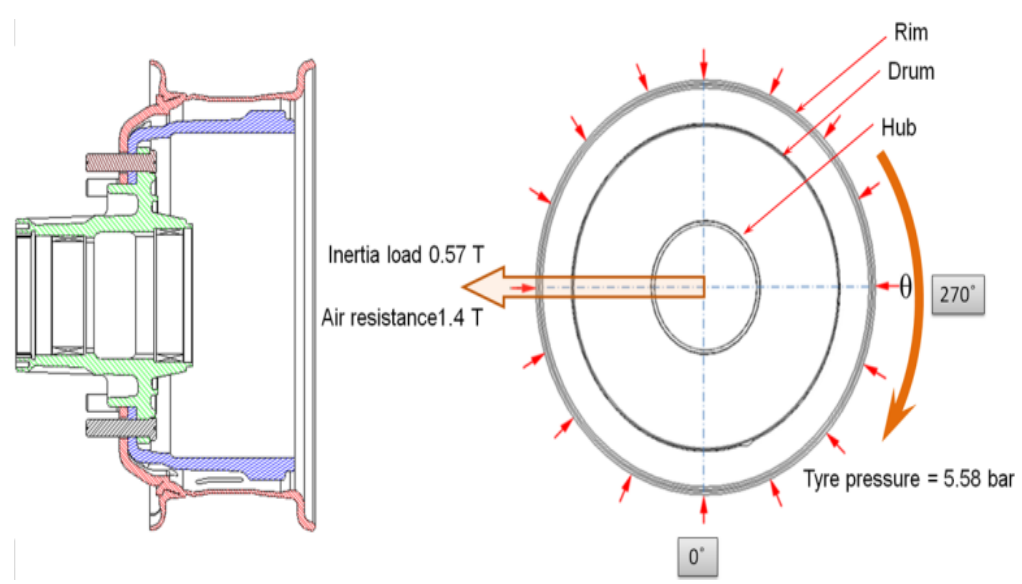

Figure 7. Tyre pressure, air resistance and inertia force

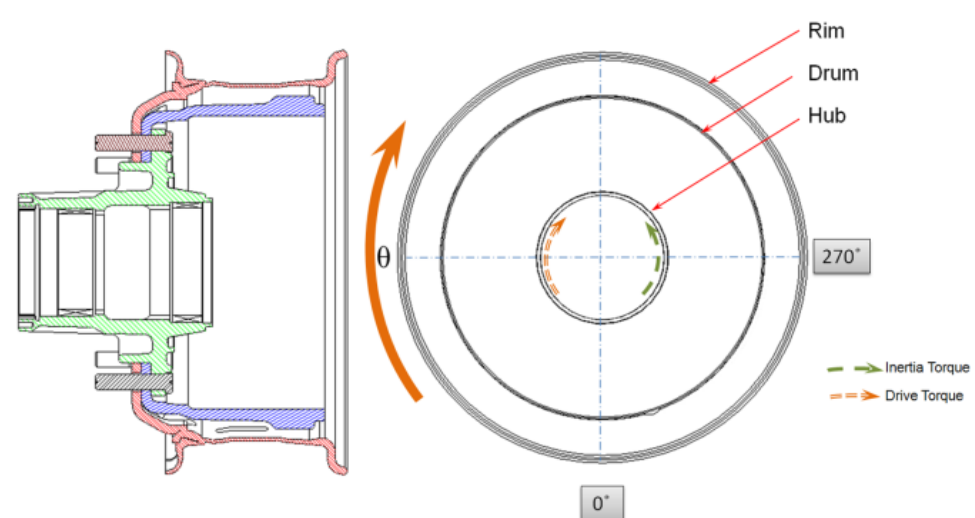

Figure 8. Input torques while driving

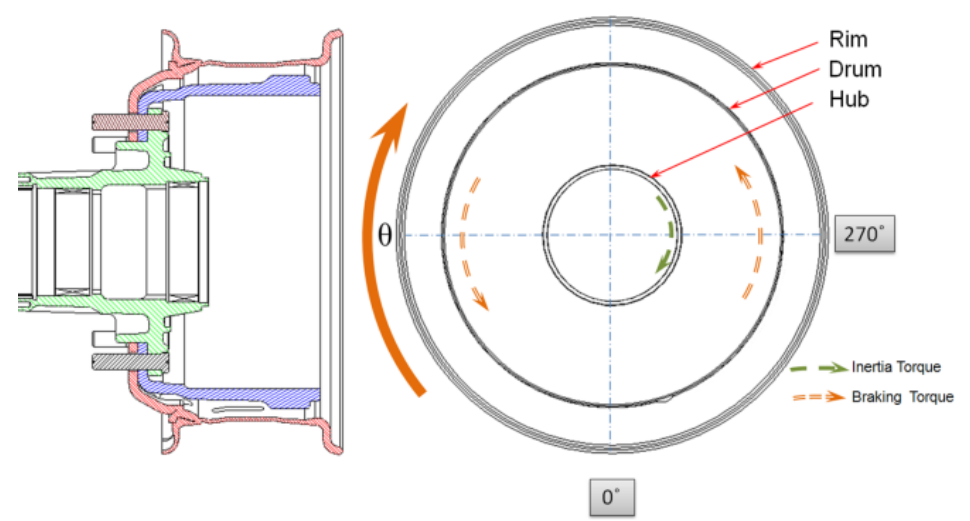

Figure 9. Input torques while braking

\section{Finite Element Analysis of drive assembly using 3D Brick Element:}

The rim is attached with drum with the help of ten mounting bolts with ribs to provide adequate stiffness to the hub assembly. Since the ideal element to model the wheel assembly is 3D brick element. But the 3D brick will takes enormous amount of time to do transient analysis during braking. Hence as a conservative estimate the analysis is confined to driving torque and braking torque of maximum intensity.

\subsection{Finite Element details}

The leading dimensions of the three parts are shown in Figure 5 and the brake drum details in Table 3 . The boundary conditions are shown in Figure 6 and loading conditions are shown in Figures 7, 8 and 9. The 3D brick 
element used for modelling is shown in Figure 10. While driving the hub gets the input torque through splines. While braking, $220^{\circ}$ of brake shoe applies the brake torque. Hub bearing seating region is cylindrically supported. Radial and axial displacements are assumed to zero in these locations. The results, using ANSYS 14 software, for the three cases discussed are shown in Figure 11, 12, 13 and in Table 4.
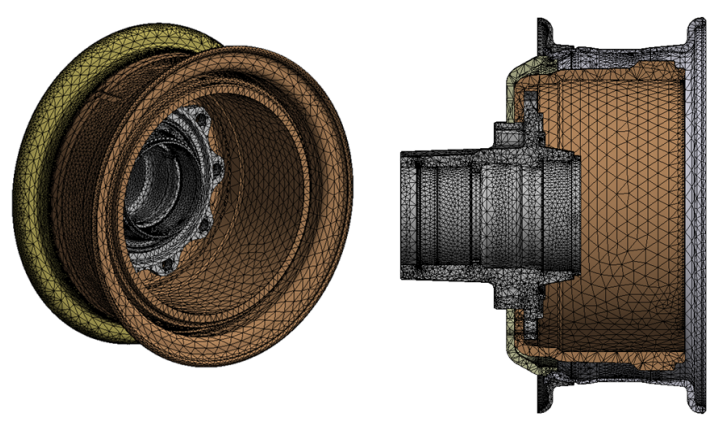

Element Type: 3D Brick Element

(SOLID 187)

Number of Nodes: $5,90,000$

Number of Elements: 3,50,000

Figure 10. Three dimensional-mesh details

Hub

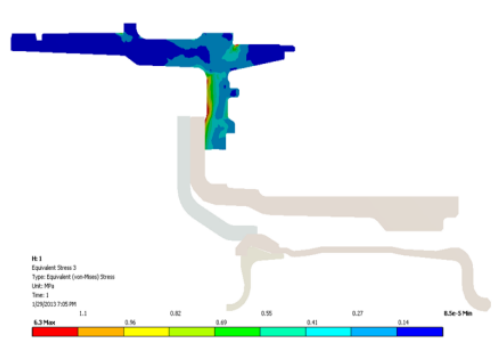

von-Mises Stress range

0.4-1.0 MPa

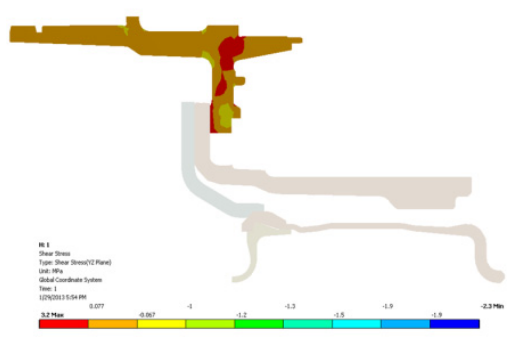

Shear Stress range

0.1-0.3 MPa
Drum

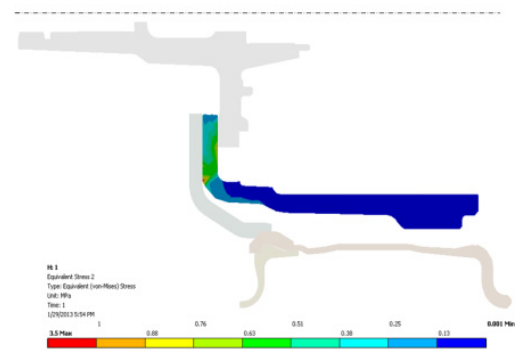

von-Mises Stress range 0.5-0.7 MPa

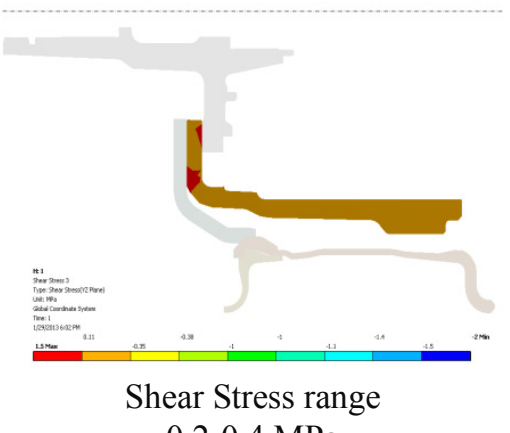

0.2-0.4 MPa
Rim

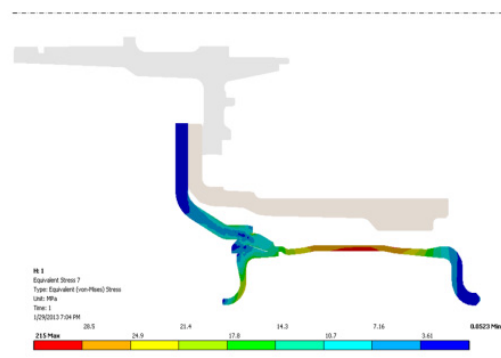

von-Mises Stress range 25-29 MPa

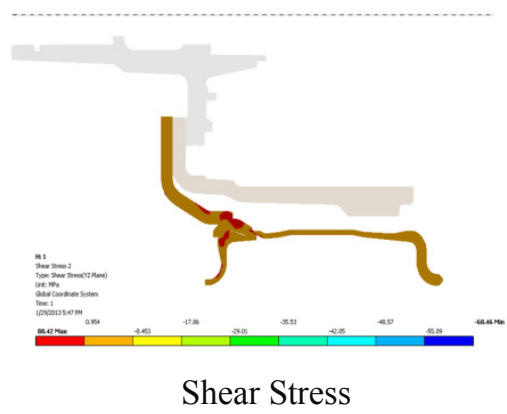

12-15 $\mathrm{MPa}$

Figure 11. Stress plot for air pressure 5.58 bar (Brick element section at $\theta=0^{\circ}$ ) 
Hub

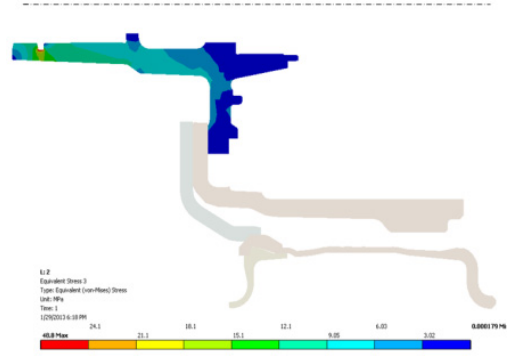

von-Mises Stress range:

3 to $15 \mathrm{MPa}$

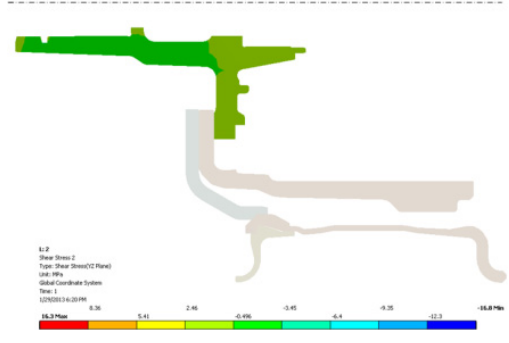

Shear Stress range

0.35 to $2.5 \mathrm{MPa}$
Drum

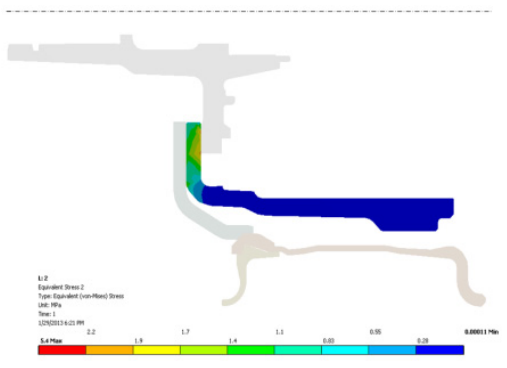

von-Mises Stress range

0.3 to $2.0 \mathrm{MPa}$

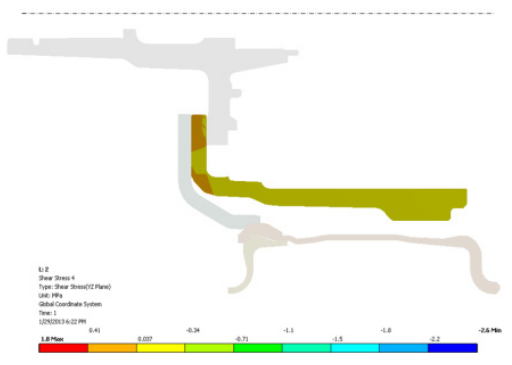

Shear Stress range

0.4 to $0.4 \mathrm{MPa}$
$\operatorname{Rim}$
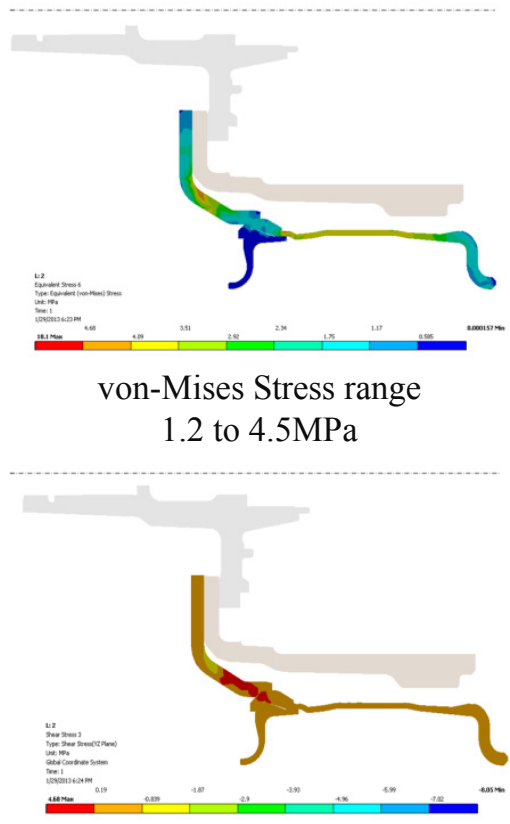

Shear Stress range

0.8 to $0.2 \mathrm{MPa}$

Figure 12. Stress plot for driving torque $4100 \mathrm{Nm}$ (Brick element section on $\theta=0^{\circ}$ )

Hub

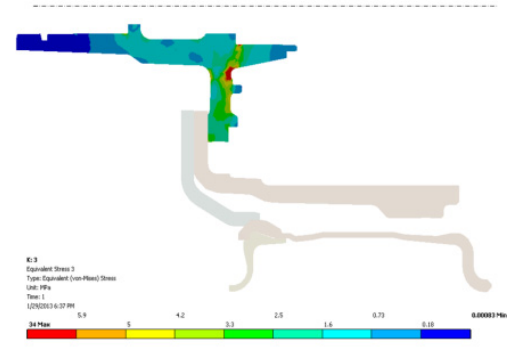

von-Mises Stress range 0.5 to $5 \mathrm{MPa}$

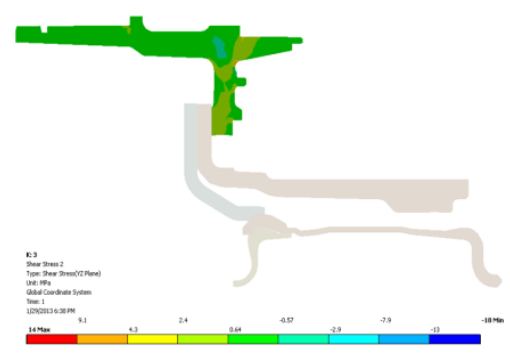

Shear Stress range 0.5 to $3 \mathrm{MPa}$
Drum

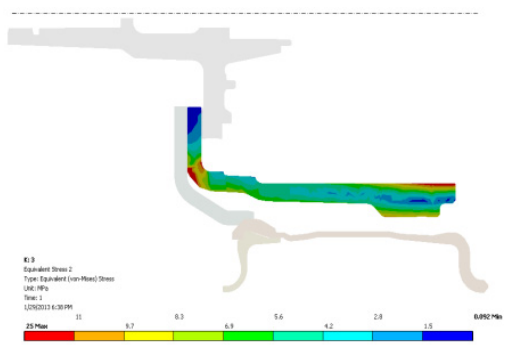

von-Mises Stress range

1.5 to $8 \mathrm{MPa}$

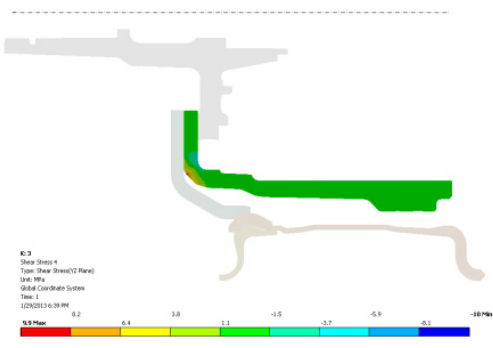

Shear Stress range 1.5 to $2.5 \mathrm{MPa}$
Rim

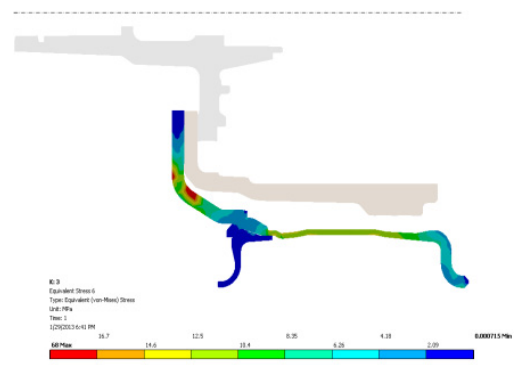

von-Mises Stress range

2 to $12.5 \mathrm{MPa}$

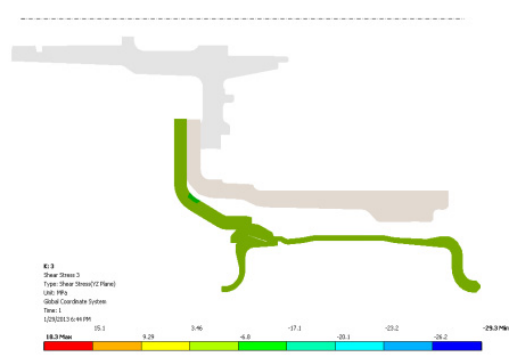

Shear Stress range 7 to $3.5 \mathrm{MPa}$

Figure 13. Stress plot braking torque $14700 \mathrm{Nm}$ (Brick element section on $\theta=90^{\circ}$ )

\section{Observation}

From Figures 11, 12, 13 and Table 4, it is clear that rim has the most stresses due to air pressure. In the case of drive torque it is the hub and for the braking torque it is the drum. This is obvious since the rim experiences the air pressure directly, the hub the driving torque and the drum the braking torque. 
Table 4. Analysis Summary/3D brick element

\begin{tabular}{ccccccc}
\hline \multirow{2}{*}{ Description } & \multicolumn{3}{c}{$\begin{array}{c}\text { von-Mises Stress } \\
\text { (MPa) }\end{array}$} & & \multicolumn{3}{c}{$\begin{array}{c}\text { Shear stress } \\
\text { (MPa) }\end{array}$} \\
\cline { 2 - 7 } & Hub & Drum & Rim & Hub & Drum & Rim \\
\hline Tyre pressure & $0.4-1$ & $0.5-0.7$ & $25-29$ & $0.1-0.3$ & $0.2-0.4$ & $12-15$ \\
Drive torque & $3-15$ & $0.3-2$ & $1.2-4.5$ & $-0.35-2.5$ & $-0.4-0.4$ & $-0.8-0.2$ \\
Brake torque & $0.5-5$ & $1.5-8$ & $2-12.5$ & $-0.5-3$ & $-1.5-2.5$ & $-7-3.5$ \\
\hline
\end{tabular}

\section{Finite Element Analysis Using the Concept of Axisymmetry Subjected to Asymmetric Loading}

Figure 14 shows the brake drum under the action of the brake shoe exerting a frictional torque. Even though the assembly of drum, rim and hub is not ideally axisymmetric in this approach axisymmetric element is used as shown in Figure $14\left(\right.$ at $\left.\theta=0^{\circ}\right)$. Since the braking torque is acting only for $220^{\circ}$ around the circumference, it may be assumed to be the sum of a finite number of harmonics. For a function symmetric about the line $\theta=0^{\circ}$ Fourier series can be written as

$$
\left.\begin{array}{l}
a_{0}=\frac{1}{2 \pi} \int_{0}^{2 \pi} f(\theta) d \theta \\
a_{n}=\frac{1}{\pi} \int_{0}^{2 \pi} f(\theta) \cos n \theta d \theta \\
b_{n}=\frac{1}{\pi} \int_{0}^{2 \pi} f(\theta) \sin n \theta d \theta
\end{array}\right\}
$$

The loading due to tyre pressure is in the radial direction and is represented by ISYM $=1$ (symmetry), in ANSYS 14 and the braking torque in the circumferential direction by ISYM $=-1$ (anti symmetry).

\subsection{Modelling}

The two cases of loads presented are one associated with radial tyre pressure and another with torques. Ignoring the bolts present, the assembly is treated axisymmetric. The element details are given in Figure 15. If this is compared with the 3D brick model is shown in Figure 10, enormous saving in computation labour when using axisymmetric will be clear.

\subsection{Fourier Harmonics for Braking Torque}

The braking torque can be expressed as two rectangular pulses as shown in Figure 14. The Fourier terms act along (given by Equation 4) the radial direction in the finite element model. PLANE 25 (ANSYS) is used for 2-D modelling of axisymmetric structures with non axisymmetric loading. The element is defined by three or four nodes having three degrees of freedom per node: translations in the radial, axial and circumferential directions. the rest of the Fourier coefficients are tabulated in Table 5.

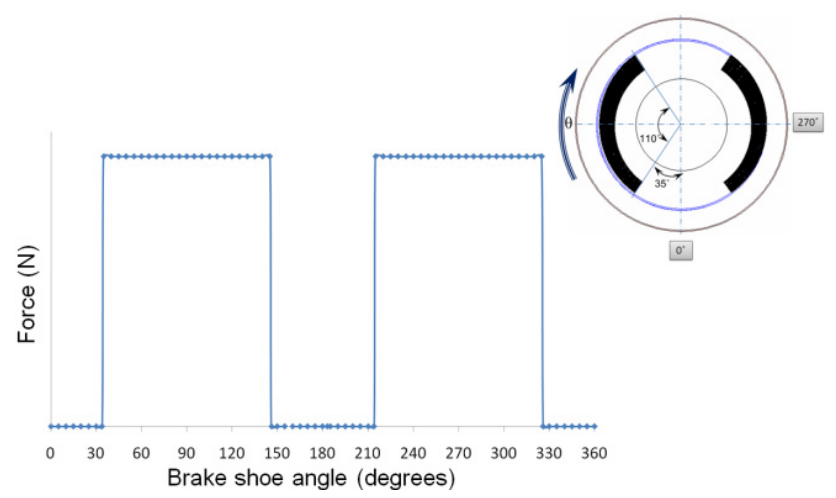

Figure 14. Brake torque distribution 
Braking force $=17703.07$

Area of rectangles $=($ angle subtended by the brake shoe/ $2 \pi) f(\theta)=\left(220^{\circ} / 2 \pi\right) \quad f(\theta)=71703.07$

Equating this $f(\theta)=18.67 \times 10^{3}$

$$
\left.\begin{array}{l}
\mathrm{a}_{0}=\frac{1}{2 \pi} \int_{0}^{2 \pi} f_{\theta} d \theta \\
\mathrm{a}_{0}=\frac{1}{2 \pi} f_{\theta}\left[\int_{35}^{145} \mathrm{~d} \theta+\int_{215}^{325} \mathrm{~d} \theta\right]=0.61 f_{\theta} \\
a_{n}=\frac{1}{\pi} \int_{0}^{2 \pi} f(\theta) \cos n \theta d \theta \\
a_{2}=\frac{f(\theta)}{\pi}\left[\int_{35}^{145} \cos 2 \theta \mathrm{d} \theta+\int_{215}^{325} \cos 2 \theta \mathrm{d} \theta\right] \\
a_{2}=-0.5982 f(\theta)
\end{array}\right\}
$$

The brake torque converges within 10 terms as seen from Table 5 .

Table 5. Fourier terms for braking torque

\begin{tabular}{cc}
\hline Harmonics Number $(\mathrm{n})$ & Fourier terms for braking torque \\
\hline 0 & 0.61 \\
1 & 0 \\
2 & -0.5982 \\
3 & 0 \\
4 & -0.2046 \\
5 & 0 \\
6 & 0.1061 \\
7 & 0 \\
8 & 0.1567 \\
9 & 0 \\
10 & 0.0221 \\
\hline
\end{tabular}

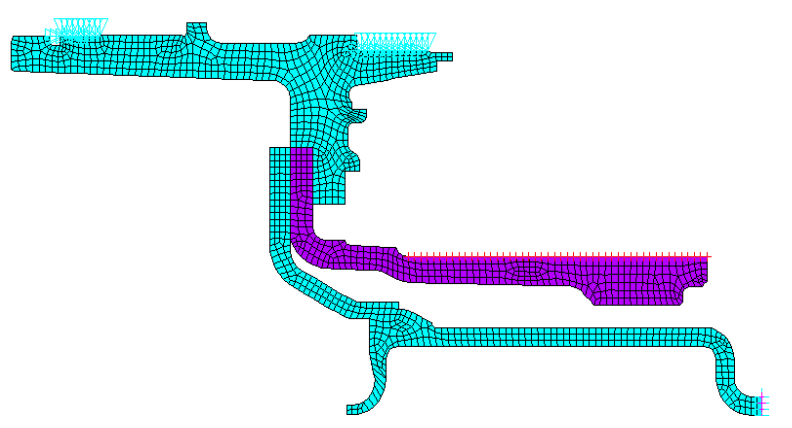

Element Type: Axisymmetric Element (PLANE 25)

Number of Nodes: 1664

Number of Elements: 1361

Figure 15. Axial section of axisymmetric model 
Hub

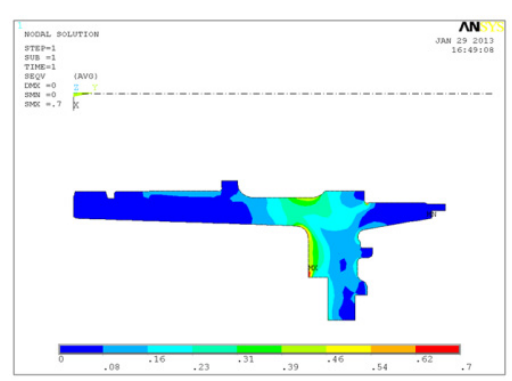

von-Mises Stress range

0.2 to $0.5 \mathrm{MPa}$

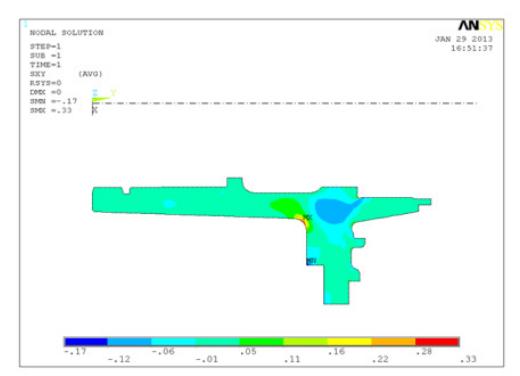

Shear Stress range

0.1 to $0.2 \mathrm{MPa}$
Drum

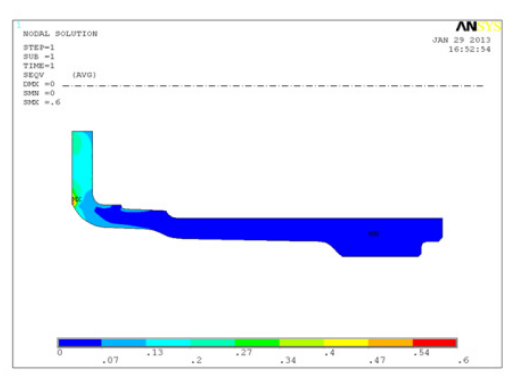

von-Mises Stress range

0.1 to $0.3 \mathrm{MPa}$

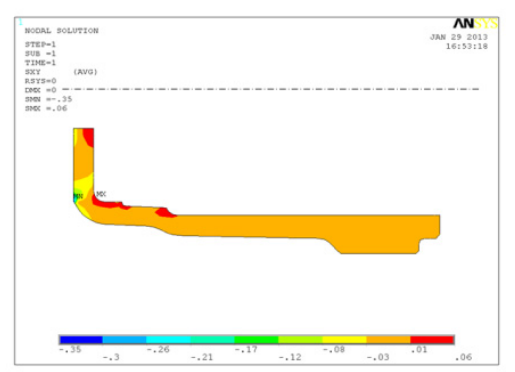

Shear Stress range

$<0.1 \mathrm{MPa}$
Rim

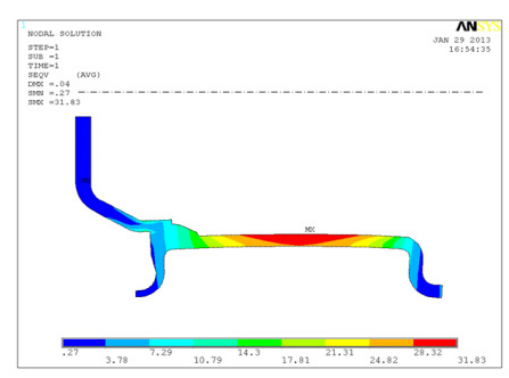

von-Mises Stress range 4-28 MPa

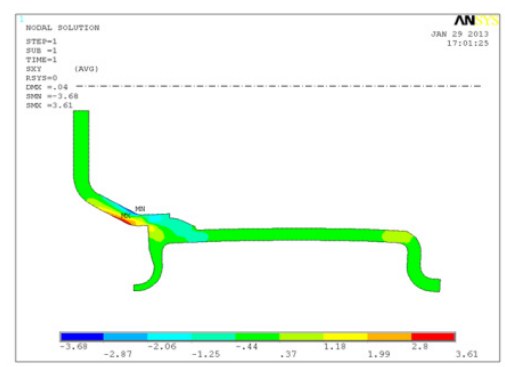

Shear Stress range -0.4 to $2.0 \mathrm{MPa}$

Figure 16. Stress plot for air pressure 0.558 bar (axisymmetric element section at $\theta=0^{\circ}$ )

Hub

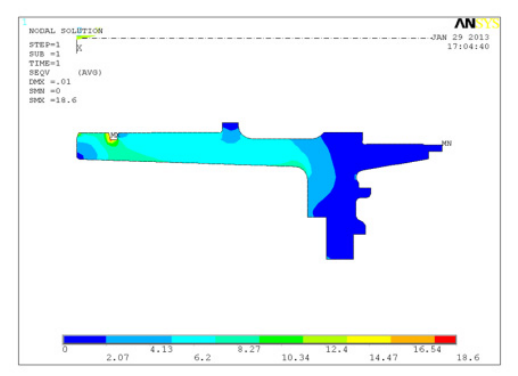

von-Mises Stress range:

4 to $10.3 \mathrm{MPa}$

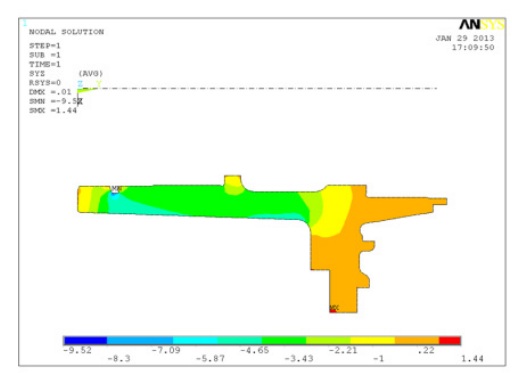

Shear Stress range:

-4.6 to $0.20 \mathrm{MPa}$
Drum

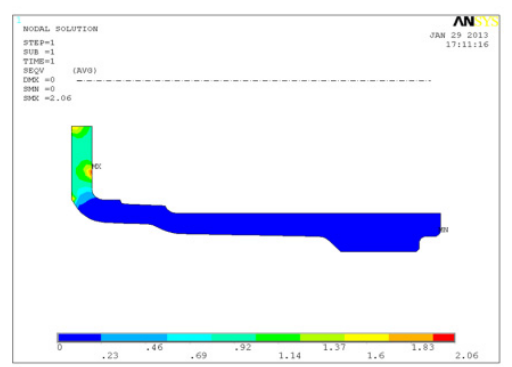

von-Mises Stress range:

0.4 to $1.4 \mathrm{MPa}$

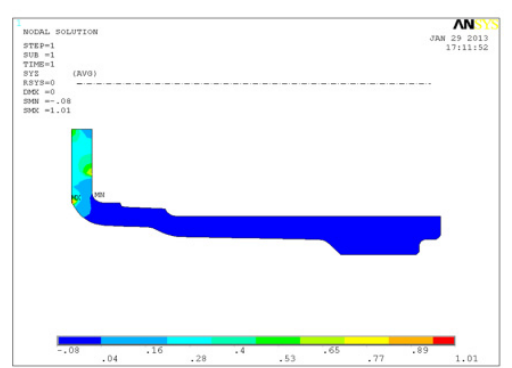

Shear Stress range:

-0.1 to $0.5 \mathrm{MPa}$
Rim

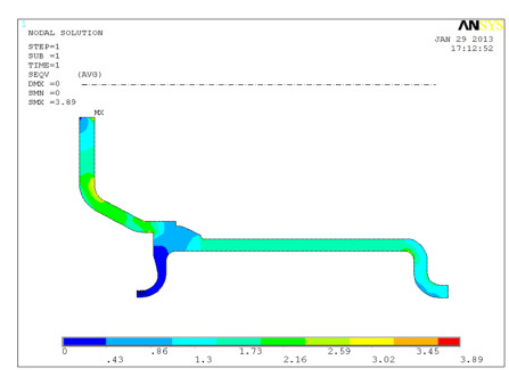

von-Mises Stress range: 0.4 to $2.6 \mathrm{MPa}$

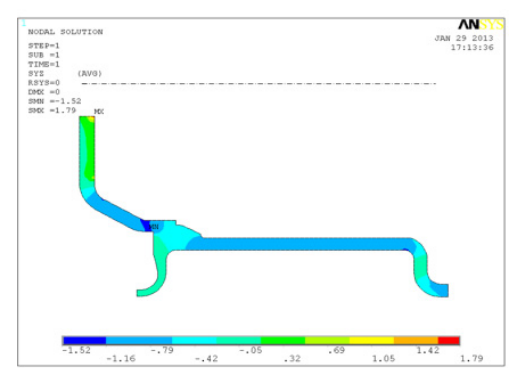

Shear Stress range: -1.2 to $0.3 \mathrm{MPa}$

Figure 17. Stress plot for driving torque $4100 \mathrm{Nm}$ (axisymmetric element section at $\theta=0^{\circ}$ ) 
$\mathrm{Hub}$

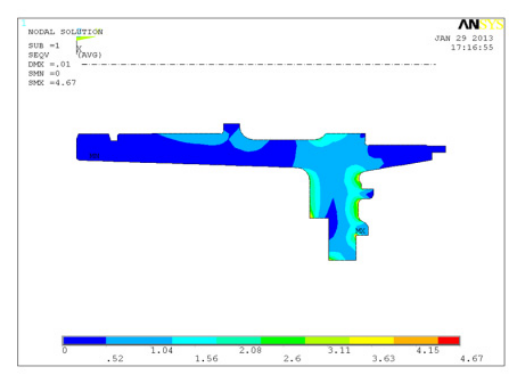

von-Mises Stress range

0.5 to $3.5 \mathrm{MPa}$

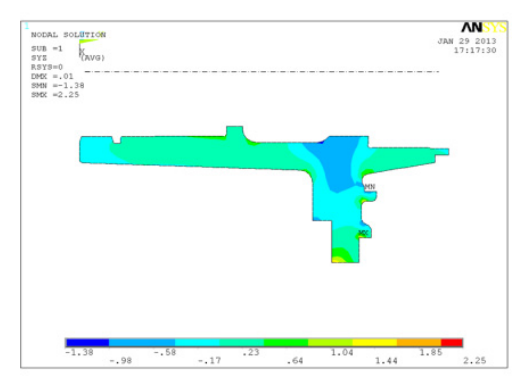

Shear Stress range

-1 to $0.6 \mathrm{MPa}$
Drum

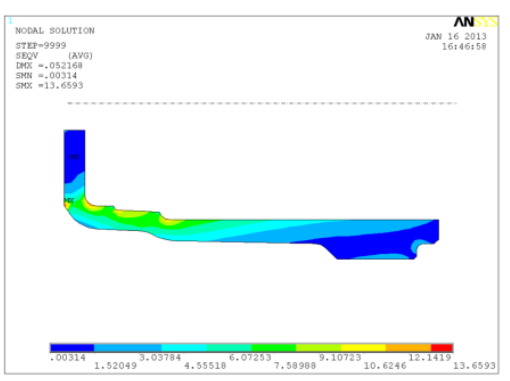

von-Mises Stress range

1.5 to $9 \mathrm{MPa}$

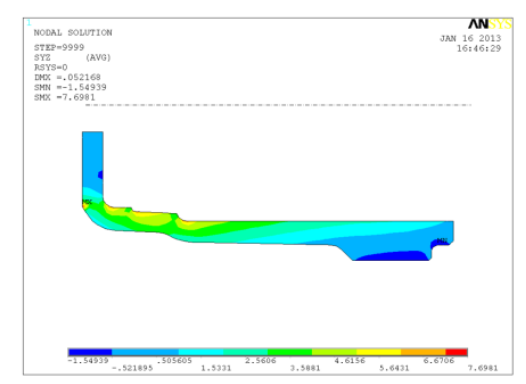

Shear Stress range

-1.5 to $2.6 \mathrm{MPa}$
Rim

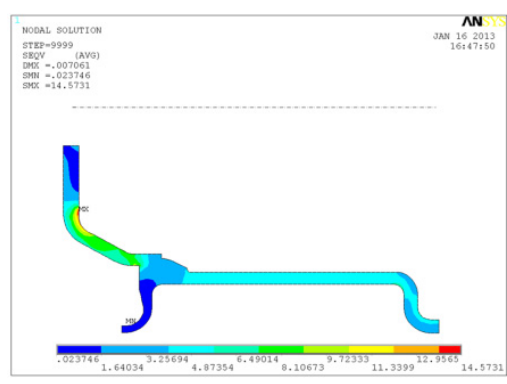

von-Mises Stress range

1.5 to $11 \mathrm{MPa}$

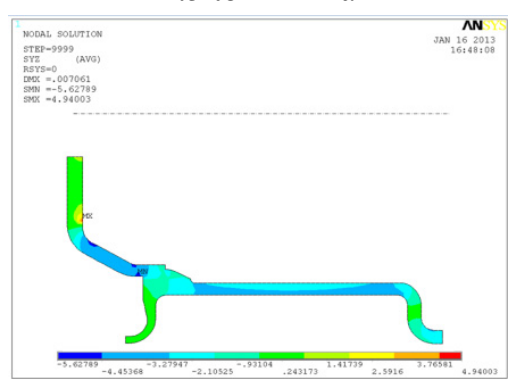

Shear Stress range

-5.5 to $2.6 \mathrm{MPa}$

Figure 18. Stress plot braking torque $14700 \mathrm{Nm}$ (axisymmetric element section at $\theta=90^{\circ}$ )

The results using axisymmetric element are shown in Figures 16, 17 and 18. The summary is presented in Table 6. The results presented in Tables 4 and 6 agree quite well.

Table 6. Analysis summary/Axisymmetric element

\begin{tabular}{|c|c|c|c|c|c|c|}
\hline \multirow[t]{2}{*}{ Description } & \multicolumn{3}{|c|}{$\begin{array}{c}\text { von-Mises Stress } \\
\text { (MPa) }\end{array}$} & \multicolumn{3}{|c|}{$\begin{array}{c}\text { Shear stress } \\
\text { (MPa) }\end{array}$} \\
\hline & Hub & Drum & Rim & Hub & Drum & Rim \\
\hline Tyre pressure & $0.2-0.5$ & $0.1-0.3$ & $4-28$ & $0.1-0.2$ & $<0.1$ & $0.4-2$ \\
\hline Drive torque & $4-10.3$ & $0.4-1.4$ & $0.4-2.6$ & $4.6-0.2$ & $0.1-0.5$ & $1.2-0.3$ \\
\hline Brake torque & $0.5-3.5$ & $1.5-9.0$ & $1.5-11$ & $-1-0.6$ & $-1.5-2.6$ & $-5.5-2.6$ \\
\hline
\end{tabular}

\section{Dead Load}

So far in the two different approaches the stress obtained due to radially inward air pressure, drive torque and brake torque. The dead load carried by this drive unit has not been considered it gives rise to a pressure pcos $\theta$ along the radial direction and $-p \sin \theta$ along the circumferential direction on the rim with the angle $\theta$ varying from -90 to +90 degrees as shown in Figure 19.

The stress distribution on the three members hub, drum and the rim, the combined stress due to the driving torque and braking torque are shown in Figures 20 and 21. The ranges of stresses expressed are tabulated in Table 7. 


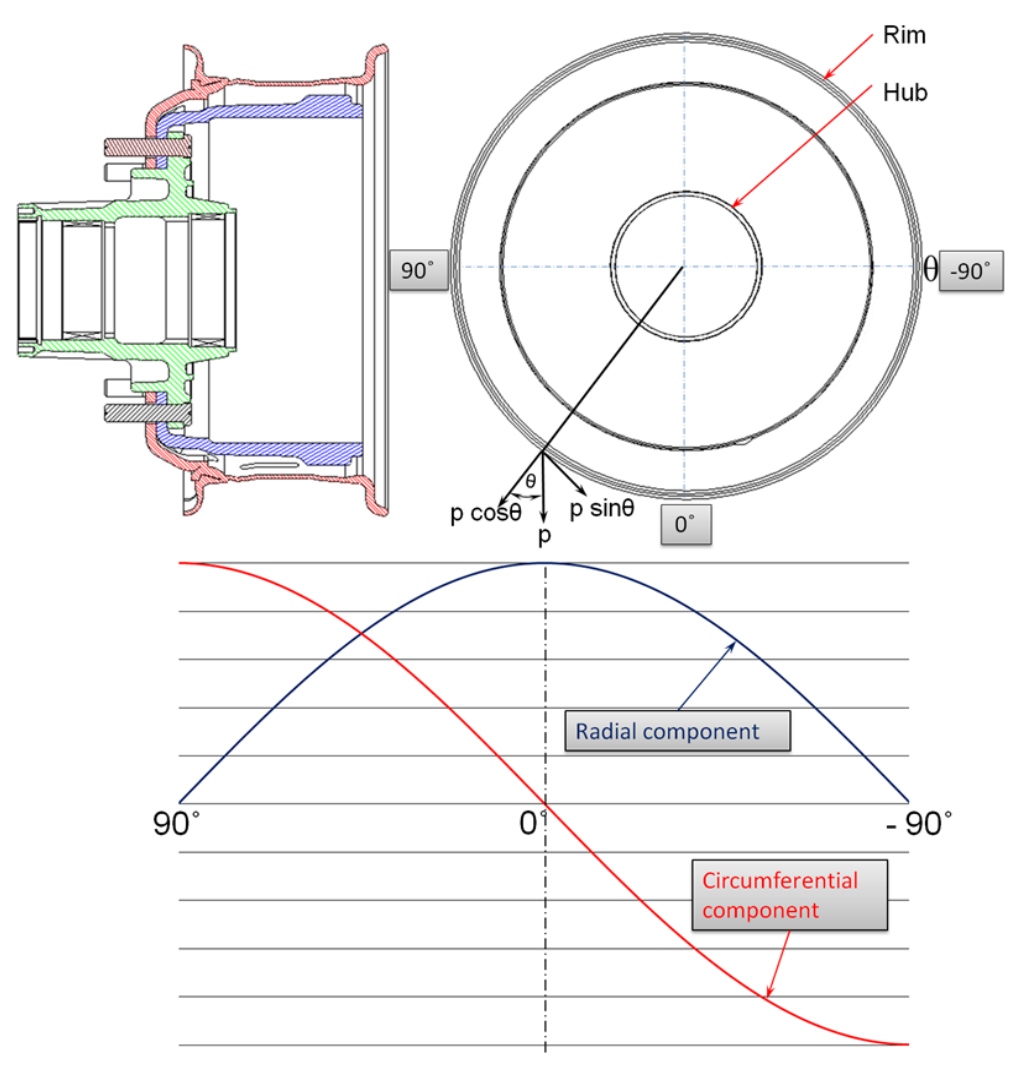

Figure 19. Dead load distribution

Hub

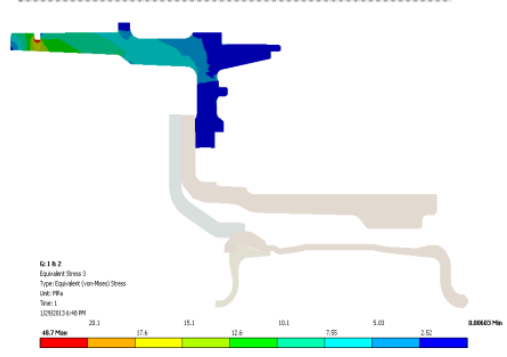

von-Mises Stress: 2.5-20 MPa

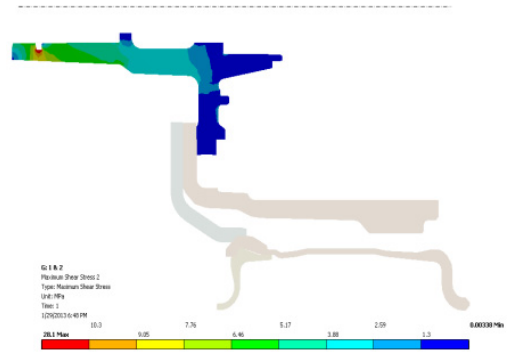

Shear Stress: 1.3-9 MPa
Drum

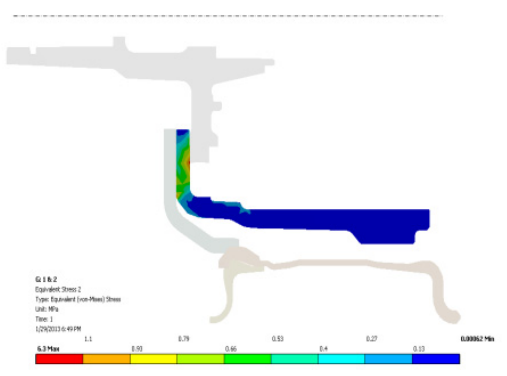

von-Mises Stress: 0.2-1.7 MPa

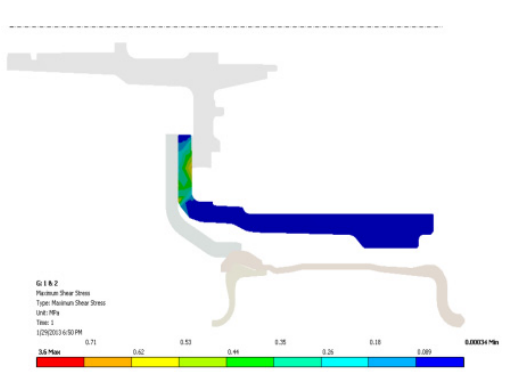

Shear Stress: 0.5-1.2 MPa
Rim
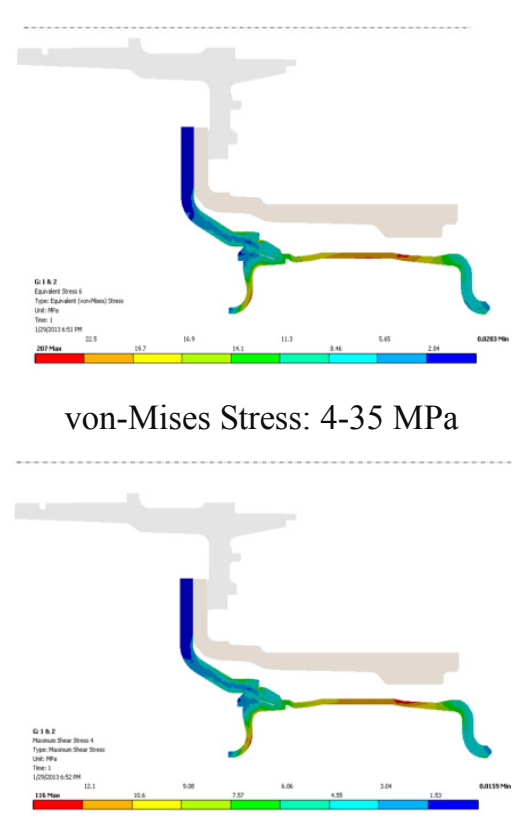

Shear Stress: 2-13 MPa

Figure 20. Stress plot vehicle load of $40000 \mathrm{~N}$ and drive torque of $4100 \mathrm{Nm}$ 
$\mathrm{Hub}$

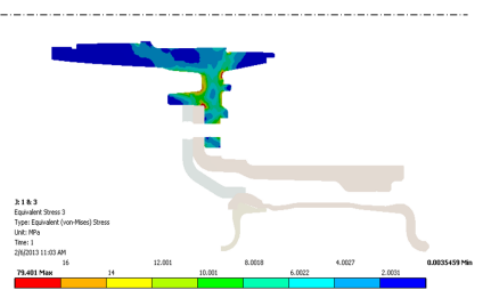

von-Mises Stress: 2-8 MPa

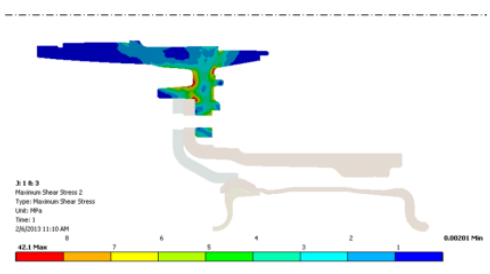

Shear Stress: 4-16 MPa
Drum

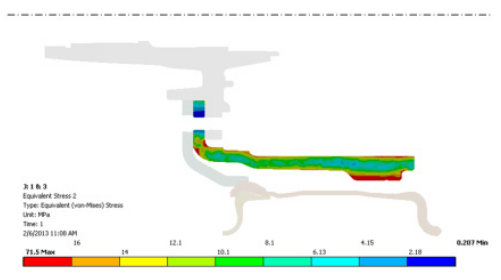

von-Mises Stress: 6-16 MPa

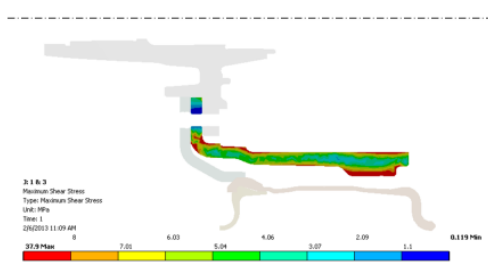

Shear Stress: 3-8 MPa
Rim

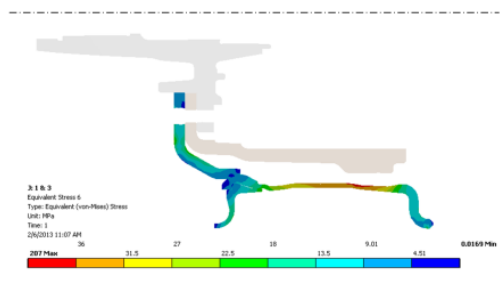

von-Mises Stress: 4-36 MPa

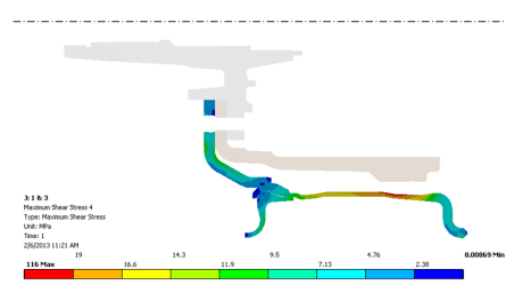

Shear Stress: 2-19 MPa

Figure 21. Stress Plot Vehicle Load of $40000 \mathrm{~N}$ and Braking Torque of $14700 \mathrm{Nm}$

Table 7. Analysis summary/combined cases

\begin{tabular}{lllllll}
\hline \multirow{2}{*}{\begin{tabular}{l} 
Description \\
\cline { 2 - 7 }
\end{tabular}} & \multicolumn{3}{c}{ von-Mises Stress } & \multicolumn{2}{c}{ Shear stress } \\
\cline { 2 - 7 } & Hub & Drum & Rim & Hub & Drum & Rim \\
\hline $\begin{array}{l}\text { Vehicle load, tyre pressure \& } \\
\text { Drive torque }\end{array}$ & $2.5-20$ & $0.2-1.7$ & $4-35$ & $1.3-9$ & $0.5-1.2$ & $2-18$ \\
\hline $\begin{array}{l}\text { Vehicle load, tyre pressure } \& \\
\text { brake torque }\end{array}$ & $4-16$ & $6-16$ & $4-36$ & $2-8$ & $3-8$ & $2-19$ \\
\hline
\end{tabular}

\section{Conclusion}

It is observed that while driving and while braking, the rim experiences a maximum stress of $35 \mathrm{MPa}$ and $36 \mathrm{MPa}$, the hub 20 and $16 \mathrm{MPa}$ and the drum 1.7 and $16 \mathrm{MPa}$. This is on the assumption that the drive and brake torque are not varying with time, since these are transient in nature the actual stress experienced are likely to approximately twice the values computed. Even then the maximum will be far less than the endurance limit of carbon steel (hub), mild steel (rim) and cast iron (drum) as seen from Table 2. The detailed procedure for analysis outlined in this paper can be conveniently used for similar drive units.

Besides, Table 7 indicates that the maximum stress experienced by the drum is only 16MPa. However it has to be admitted, that there is a steep temperature variation on the brake drum during braking both along the circumference and across the depth. There are no documented values of temperature variation available. If this taken into account the maximum stress experienced by the drum is likely to be much higher than $16 \mathrm{MPa}$.

\section{Acknowledgements}

The authors gratefully acknowledge the support given by Messer's WABCO India Limited, Chennai in carrying out this investigation and permitting publication of this article in a journal.

\section{References}

Bert, B., \& Bill, K. H. (2008). Brake Technology HandBook. SAE International Pennsylvania,USA.

Cao, F., Gao, T., Jiao, J., Pan, T., \& Xing, Z. (2009). Study of a screw rotor with different stocks and leads for a twin-screw multiphase pump. Proceedings of the Institution of Mechanical Engineers, Part C: Journal of Mechanical Engineering Science, 223(11), 2637-2645. http://dx.doi.org/10.1243/09544062JMES1476 
Croccolo, D., \& Vincenzi, N. (2009). A generalized theory for shaft-hub couplings. Proceedings of the Institution of Mechanical Engineers, Part C: Journal of Mechanical Engineering Science, 223(10), 2231-2239. http://dx.doi.org/10.1243/09544062JMES1437

Day, A. J. (1991). Drum Brake Interface Pressure Distribution. Proc. I. Mech. E., 205, 127-136. http://dx.doi.org/10.1243/PIME_PROC_1991_205_162_02

Fenina, S., Fakhfakh, T., \& Haddar, M. (2008). Dynamic behaviour of V-belt drive system in the presence of sheaves' lateral misalignment. Proceedings of the Institution of Mechanical Engineers, Part C: Journal of Mechanical Engineering Science, 222(9), 1673-1679. http://dx.doi.org/10.1243/09544062JMES861

Paynter, R. J. H., Hills, D. A., \& Barber, J. R. (2009). Features of the stress field at the surface of a flush shrink-fit shaft. Proceedings of the Institution of Mechanical Engineers, Part C: Journal of Mechanical Engineering Science, 223(10), 2241-2247. http://dx.doi.org/10.1243/09544062JMES1403

Popovic, P., Ivanovic, G., Mitrovic, R., \& Subic, A. (2012). Design for reliability of a vehicle transmission system. Proceedings of the Institution of Mechanical Engineers, Part D: Journal of Automobile Engineering, 226(2), 194-209. http://dx.doi.org/10.1177/0954407011416175

Ramamurti,V. (2009). Finite Element Method in Machine Design. New Delhi: Narosa Publishing House.

Rose, A. T. J. M., Akehurst, S., \& Brace, C. J. (2011). Modelling the performance of a continuously variable supercharger drive system. Proceedings of the Institution of Mechanical Engineers, Part D: Journal of Automobile Engineering, 225(10), 1399-1414. http://dx.doi.org/10.1177/0954407011406320

Sun, Y., Zhou, X., Wei, L., \& Wang, W. (2009). Development of a new type of transmission screw nut with high efficiency and heavy duty characteristics. Proceedings of the Institution of Mechanical Engineers, Part C: Journal of Mechanical Engineering Science, 223(5), 1181-1189. http://dx.doi.org/10.1243/09544062JMES1332

Tirovic, M., \& Day, A. J. (1991). Disc brake interface pressure distributions. Proc. I. Mech. E., Part D, 205, 137-146. http://dx.doi.org/10.1243/PIME_PROC_1991_205_162_02

Wong, J. Y. (2001). Theory of ground vehicles. New York, NY: John Wiley \& Sons, Inc. 